\title{
Dictionary Use of Undergraduate Students in Foreign Language Departments in Turkey at Present
}

\author{
Ayşegül Takkaç Tulgar \\ English Language Teaching Department, Atatürk University, Turkey
}

Copyright $\bigcirc 2017$ by authors, all rights reserved. Authors agree that this article remains permanently open access under the terms of the Creative Commons Attribution License 4.0 International License

\begin{abstract}
Foreign language learning has always been a process carried out with the help of dictionaries which are both in target language and from native language to target language/from target language to native language. Dictionary use is an especially delicate issue for students in foreign language departments because students in those departments are expected to master the target language to a degree to enable themselves to listen, speak, read and write in the target language. In this process, the effects of new developments in technology have also exerted their influence on the way students use dictionaries mentioned above. Based on the results of classroom observations and interviews, this study is intended to shed light on the way undergraduate students in foreign language departments in Turkey use print/online dictionaries and to highlight opinions on the advantages and disadvantages of dictionary use by students in those departments at present.
\end{abstract}

Keywords Dictionary Use, Online Dictionaries, Print Dictionaries, EFL

\section{Introduction}

As language learning has become almost a necessity in the agendas of many people, the materials that are used in the process of language learning and teaching are among the topics of investigation and discussion in the field. Dictionaries have traditionally taken their unique places among the materials utilized in the journey of language teaching and learning. As indispensable sources to promote individual learning or self-directed learning (Bishop, 2000; Chan, 2011), dictionaries are of great significance to enable language learners to develop such language skills or knowledge as phonetics, pronunciation, word roots, grammar and register besides providing the meaning of the searched vocabulary item. Studies on the usages of different dictionary types have pointed at the advantages of utilizing dictionaries compared to no dictionary use (Chen, 2011; Hyun Ma \& Cheon, 2016).

As crucial self-learning tools, dictionaries have many different types considering their language basis and design. Regarding their language basis, there are monolingual dictionaries which present the explanations in the target language and bilingual dictionaries which provide explanations in native-to-target or target-to-native languages. Taking their designs into account, there are print dictionaries in hard copy forms and electronic dictionaries which can be divided into two types; online dictionaries and off-line dictionaries.

The dictionary market has taken its share from the globalization of the world and the advancements in technology. The day-by-day globalizing world has necessitated learning different languages for various purposes, which has promoted the development of dictionary content presented in different languages. The rapid expansion of technology has also drastically impacted the way language is presented and this has paved the way for online dictionaries which are grounded in the integration of the Internet in dictionary presentation and off-line dictionaries which utilize software forms through digital technologies. It is inevitable that the advent of online and off-line dictionaries has greatly influenced the preferences of dictionary users in a gradual but dramatic way. This change in dictionary preferences, therefore, can be said to have attracted the attention of researchers as they are interested in issues affecting educational processes and lexicographers as they are expected to offer the best designs and contents.

Perusal of relevant literature reveals that there are many studies on dictionary types comparing monolingual dictionaries with bilingual ones (Chan, 2011; Laufer \& Hill, 2000; Laufer \& Levitzky-Aviad, 2006), dictionary usages concerning how language learners make use of dictionaries (Laufer \& Hill, 2000; Lew \& Doroszewska, 2009) and the effects of dictionary usage on language development investigating the extent of improvement in different language skills and knowledge as a result of 
dictionary integration (Folse, 2004; Hayati \& Fattahzadeh, 2006; Lew \& Doroszewska, 2009). As this study focuses on gathering the opinions of EFL learners in terms of their preferences of print dictionaries (PD) and online dictionaries (OD), literature centering on print dictionaries and online/off-line electronic dictionaries as well as a comparison of both print and electronic dictionaries will be presented. One of the earliest studies making a comparison between paper dictionaries and online dictionaries was conducted by Koga (1995), who reported that online dictionaries were more helpful compared to print versions for those participants with higher reading scores while there was no significant difference considering the group with lower reading scores. Supporting the contributory nature of electronic dictionaries over print ones, Laufer (2000) found that the group using electronic versions got significantly higher scores than the print dictionary-users. Successive studies were carried out by Koyama and Takeuchi (2003, 2004, 2007). In their 2003 study, the researchers aimed to compare print and electronic dictionaries and reported no significant difference between two dictionary types in terms of the number of searched items, look-up time and word retention scores. In their following study (2004) on the comparison of print and electronic dictionaries, they found little difference considering word retention between PD and ED in favor of PD usage. In two subsequent studies examining the effectiveness of two dictionary types on reading comprehension, Koyama and Takeuchi (2004, 2007) noted that the comparatively more frequent and quicker usages of EDs did not make differences in the reading comprehensions of the participants.

Sharing similar results with those of the above-mentioned studies, Chen (2010) investigated the extent to which vocabulary learning can be affected by print or electronic dictionary use. The results revealed that there were not statistically significant differences in participants' comprehending, producing and remembering vocabulary items searched through PDs or EDs. Expanding the scope of the previous design, Chen (2011) added, besides PD and ED-users, a new group of participants who were asked to adopt guessing strategies instead of using any dictionary types. The results, pointing to the advantage of using dictionaries over no-dictionary use, showed that there were not statistically significant differences between the PD and ED groups. Another study which resulted in counter evidence indicative of the superiority of online dictionary forms over print ones was conducted by Dziemianko (2010). The researcher informed that online dictionaries were more influential in helping learners through receptive and productive tasks as well as recalling the searched words and collocations. On the other hand, two consecutive studies (Dziemianko, 2011 , 2012) did not support the findings of the previous one as they did not unearth the superiority of EDs over PDs regarding the same variables (word reception, production and retention).

The consideration of literature on dictionary use and types of dictionaries reveals that existing research has handled the issue from more or less similar aspects as they are generally based on making a comparison of two dictionary types with an aim to find their effectiveness. However, these studies utilized experimental designs to search the effectiveness of two dictionary types. There are no studies, known to the researcher, examining learners' dictionary preferences from a qualitative perspective. Besides, there is scarcity of research centering on dictionary use in foreign language learning in Turkish context. Therefore, in the light of relevant literature, the present study, based on a qualitative design, is purposed to investigate the opinions of EFL learners regarding their preferences of using two types of dictionaries; print dictionaries and online dictionaries.

\section{Methodology}

This qualitative study aimed to reach a deep understanding of the views of Turkish learners of English in EFL context as regards their dictionary use and their preferences of dictionary types. For this purpose, classroom observations and semi-structured interviews were utilized for data collection. The classroom observations were conducted during a whole term in the Turkish-English Translation course. The instructor-researcher took notes of her observation focusing on which type/s of dictionaries students $(n=71)$ preferred to use, how frequently they were using dictionaries and what content they were going through while using dictionaries (word meaning, pronunciation, grammatical information, etc.).

Towards the end of the term, a group of 12 students who were observed to frequently use dictionaries and to benefit from both print and online dictionaries were asked to take part in interviews. Semi-structured interviews with these participants were individually conducted and each interview lasted about 20 minutes. The interview questions were about their perceptions of dictionary use and dictionary preferences. The data obtained through the interviews and observation notes were analyzed through content analysis in order to clearly picture the dictionary usages and preferences of a group of Turkish learners of English in EFL context.

\section{Results and Discussion}

The results obtained through the interviews and classroom observations revealed that almost all the participants preferred to benefit from dictionaries in their language education though there were differences in their choices of dictionary types. They favored dictionary 
integration over no-dictionary-use. Also, most of them explained that using dictionaries during courses or language-related tasks contributed to their language knowledge and skills in addition to providing mere explanations. The below table presenting the results of the analysis regarding dictionary use can illustrate the views of participants.

Table 1. Participant views as regards the benefits of dictionary use

\begin{tabular}{|c|c|}
\hline \multicolumn{2}{|c|}{ Theme 1: Benefits of using dictionary } \\
\hline & $\begin{array}{c}\text { Pronunciation } \\
\text { Grammar } \\
\text { Category 1: language knowledge }\end{array}$ \\
& $\begin{array}{c}\text { Field-specific vocabulary } \\
\text { Collocations } \\
\text { Cross-checking meaning } \\
\text { Register }\end{array}$ \\
\hline Category 2: language user & Individual learning \\
\hline
\end{tabular}

As can be seen in Table 1, most of the participants had positive views as to the integration of dictionaries in language education. They shared the perspective that dictionaries are not designed only to provide word-to-word translations to convey meaning between languages. Instead, the participants believed that dictionaries are language learning materials in which language learners can find additional information about other components and aspects in the target language. A participant maintained that using dictionaries in different phases of language learning contributed to his language knowledge and helped him improve the way he used the target language:

"I think dictionaries are useful materials because they can add new things to our knowledge in the target language. In dictionaries, I don't only learn the L1-L2 translations of some vocabulary items; I can also learn how a word is pronounced, how it can be used with other items or how it can be used appropriately in different contexts."

Another participant also shared similar views and commented that dictionaries have expanded his foreign language knowledge as they involve information related with grammar, collocations and register. $\mathrm{He}$ expressed that dictionaries have helped him improve his language knowledge and skills because he can have access to word-related information beyond mere translations of items. Favoring the adoption of dictionaries in foreign language education for understanding and producing the target language, the participant stated that dictionaries are beneficial materials as they foster individual learning:

"Dictionaries are really useful because they provide much information about words. I can learn the root of a word, its collocations or how I should use it in a sentence. Without dictionaries, I think, it would be really hard to understand and use the target language. Besides, we would have to depend on the teacher to for the meaning and pronunciation of unknown words."
The in-class observation notes also pointed at the frequent adoption of dictionaries by EFL students especially during translation courses. Although they used different types of dictionaries, all the participants were observed to favor the integration of dictionaries in foreign language learning process. In the light of the observation notes and participant quotations, it can be inferred that integrating dictionaries in language education is of great benefit to students' development in learning additional information related to the looked-up item. This result has also been supported by some studies (Bishop, 2000; Chen, 2011; Hyun Ma \& Cheon, 2016; Ranalli, 2013). Instead of simply offering word-by-word translations or explanations, dictionaries with comprehensive content can equip learners with language-related information which can assist them in foreign language learning process. In a broader sense, well-designed dictionaries can equip learners with increasing their vocabulary knowledge and appropriate language use, which helps improve their reading, writing, listening and speaking skills. Besides, offering learners some pragmatic knowledge like how, where and with which item to use a particular word, dictionaries can become rich sources of information for individual learning promoting some degree of independence and autonomy in learners.

Table 2. Print vs. electronic dictionaries

\begin{tabular}{|c|c|}
\hline \multicolumn{2}{|c|}{ Theme 2: Print vs. online dictionaries } \\
\hline $\begin{array}{c}\text { Category 1: Advantages of print } \\
\text { dictionaries }\end{array}$ & $\begin{array}{c}\text { Chances of learning new items } \\
\text { More detailed } \\
\text { Example sentences } \\
\text { More healthy }\end{array}$ \\
\hline $\begin{array}{c}\text { Category 2: Disadvantages of print } \\
\text { dictionaries }\end{array}$ & $\begin{array}{c}\text { Not practical } \\
\text { Time-consuming } \\
\text { Not technological }\end{array}$ \\
\hline $\begin{array}{c}\text { Category } 3 \text { : Advantages of online } \\
\text { dictionaries }\end{array}$ & $\begin{array}{c}\text { Technological } \\
\text { Quick search } \\
\text { Audio for pronunciation } \\
\text { Easy access }\end{array}$ \\
\hline $\begin{array}{c}\text { Category 4: Disadvantages of } \\
\text { online dictionaries }\end{array}$ & $\begin{array}{l}\text { Less detailed } \\
\text { Loss of connection } \\
\text { Distracting images }\end{array}$ \\
\hline
\end{tabular}

Here, it should be noted that this study focused on the preference and usage of print and electronic dictionaries by EFL students. It should, again, be noted that the participants in this study were observed to use print and/or online dictionaries and did not benefit from off-line dictionaries. Some of the participants explained that though they were aware of the existence of off-line dictionaries which could be downloaded as smart phone applications and could be used like print dictionaries, they did not want to download such dictionaries because it was necessary to pay for them. Therefore, they preferred to use online dictionaries which were free and easy to download as an app like off-line dictionaries. However, even those participants who were aware of off-line dictionaries did not have much knowledge of the design and scope of off-line 
dictionaries. When told off-line dictionaries are like the software forms of print dictionaries and they offer content and presentation as rich as print forms, most of the participants stated they did not know that much. Since none of the participants used off-line dictionaries as a form of electronic dictionary, the results focused on the advantages and disadvantages of print and online dictionaries. Table 2 displays participant views on dictionary types which pointed at some advantages and disadvantages of print and online dictionaries.

As indicated in Table 2, participant comments differ according to their perceptions of the effectiveness and usefulness of print and online dictionaries. The written notes taken during classroom observations revealed that most of the participants made use of online dictionaries more frequently compared to print ones while searching for meaning. However, the data obtained through interviews showed that they generally favored the integration of print dictionaries instead of online ones for some reasons. A comment from one participant can be enlightening to understand some possible reasons behind this observed difference. The participant stated that she did not like to carry print dictionaries as they are heavy; instead, she used online dictionaries when there was access to the Internet generally through the $\mathrm{Wi}-\mathrm{Fi}$ connections in the faculty building. However, she also stated that she sometimes needed to further check for accuracy in meaning. So, when she thought the definition in the online version was not enough, she felt the need to re-check the item in a comprehensive print dictionary which was mostly available in the class as a few classmates brought them for the translation lesson. She also added that she could learn many more words in print dictionaries because there were different words on the same page, which was a shared point in the comments of most of the participants. The below statement may reveal the common view of the EFL participants in their dictionary preferences:

“Well... I really don't like to carry heavy dictionaries. It is more logical to use online sources to look up word meanings, especially for translation courses... but, sometimes I cannot be sure whether the meaning or usage in online dictionary is really true. Then, I need to check the meaning again in a print dictionary because it is much more detailed and reliable than the online one. Besides, when I look up a word in print dictionary, I can meet other words and expressions because there are many other items on the same page. This is a real advantage for foreign language learners."

Another participant who also shared a similar perspective expressed that online dictionaries are a lot more technological and practical compared to print ones, but the former is not as detailed and informative as the latter. Referring to different points, he provided a good comparison between two dictionary types referring to their advantages and disadvantages and suggested the integration of both:

"There are advantages and disadvantages of both, I think. Online dictionaries are of course more technological and they offer easy access to information. You just write the word and the dictionary gives you the meaning... But it is generally simple word-by-word translation, not more. Well... sometimes the pronunciation is available. On the other hand, print dictionaries, as far as I am concerned, have much more information; they include word meaning, pronunciation, some grammatical usages, collocations and example sentences. Besides, there are a number of other words you can see on the same page. All in all, both have advantages and disadvantages, so both should be used."

Some participants, though few in number, were observed to bring print dictionaries to class to use when searching for word meanings. During the interviews, they explained that they preferred using print dictionaries since they are much more comprehensive compared to online versions. A participant also holding a similar perspective regarding the advantage of print forms proposed an attention-grabbing reason why she preferred print dictionaries. She maintained that she prefers print dictionaries because she enjoys touching the paper material in the learning environment and is not happy to have all the foreign language learning materials in digital form, as expressed in her sentimental comment:

"I like print dictionaries because everything is digital and electronic. Of course, technology is beneficial in education but... I like touching the paper, taking notes on it. I think I enjoy conventional learning materials more."

The digital structure and featuring of online dictionaries was not the only point of criticism. The distracting images and loss of connection when using online dictionaries were also among the negative points that made some participants displeased. They complained that their attention was distracted with irrelevant pop-ups or adds in online dictionaries. Loss of connection also seems to be a source of trouble for some participants as they considered it as a waste of time. A participant stated that he prefers print dictionaries in order not to waste time:

"I hate the pop-ups in all online dictionaries, why are they there? I look up a word and I see an add; I look up another word, I see a different add... And, the loss of connection... Searching through print dictionaries may, at first sight, seem to take a long time, but in fact, there are bigger problems with online ones. I think using online dictionaries are not practical at all... Besides, they are not really reliable."

The results obtained from the observation notes also revealed common aspects referred to in participant remarks during the interviews. The researcher observed that most of 
the learners used online dictionaries during their search for meaning which was also observed in Gromann and Schnitzer's (2015) study reporting the adoption of electronic dictionaries twice as much as the print ones by all proficiency level participants. Those participants in the present study were observed to use especially online dictionaries to check for simple word meanings. However, when they needed more detailed information such as word collocations or appropriate pragmatic usage, they preferred to look up in printed dictionaries available in the class. They needed to cross-check the meaning they got from the online dictionaries. Upon this point, Carduner (2003) suggests discrediting "the individual word syndrome" ( $\mathrm{p}$. 70) and notes that learners' awareness should be raised since word-for-word translations of items do not always convey appropriate meanings.

The participants, during the interviews in this study, maintained that print dictionaries were more advantageous than online dictionaries. One of the main reasons why participants viewed print forms as more useful seems to be the amount and type of information included in print dictionaries which was also supported by some previous research findings (Bishop, 2000; Laufer \& Levitzky- Aviad, 2006). Simple word-by-word translations or explanations or the provision of fixed collocations may misinform learners and mislead them to use inappropriate forms (Yang \& Zhao, 2007). The comparatively-limited content of online dictionaries compared to print ones has been referred also by Bower \& McMillan (2007), Deng (2006) and Koyabashi (2006) who refer to electronic dictionaries and further comment that they can be more expensive and less durable than the print versions.

Another noteworthy point in participant remarks is the serendipity offered by print dictionaries. In electronic versions (online ones in this study), users enter the word and can reach the meaning in milliseconds. What they can see is only the information related to that specific item. On the other hand, in print formats, when they search for a word, learners can also see different items, meanings and usages above and below the looked-up word. Their eyes involuntarily wander on the page and some other items may attract their attention. In this way, they can learn new words or remember those they have not used for some time. This process, in some way, offers them opportunities for peripheral learning and can be viewed as a positive side effect of using print dictionaries.

Print dictionaries may receive the criticism, as stated by some participants in this study, that it takes more time to look up for a word. It is obvious that online and off-line electronic dictionaries offer users the practicality of entering the word and getting the meaning (Nesi, 1999). You don't have to go through the alphabetical order to find the searched item. Sometimes even the initial letters can be enough for the application or electronic tool to automatically give you the whole word. Yet, this presumed advantage can easily turn into a disadvantage. Language learners who can have rapid and easy access to vast amounts of information may face the danger of getting lazy and technology dependent. For example, in its simplest terms, a learner who enters the first few letters of a word and reaches the whole item and its meaning may, in time, have difficulty in writing it as a whole word without hesitation or without some spelling mistakes in actual writing performances. Though following the alphabetical order in print dictionaries may seem time-consuming, it helps learners activate their spelling skills. When learners are cognitively involved in finding the word they are searching for, the level of word retention may also increase in addition to the chance of learning new ones.

There should be some place for discussion also for the nostalgia coming along with print dictionaries. We are living in an age in which digital technology exerts its influence in many areas of human life including language education. Language teachers try to integrate digital materials into their courses via PCs or some web designs, they ask learners to follow some online sources and they ask them to submit their papers through the Internet facilities. And in this age, most learners inevitably have become technology dependent and voluntarily integrate digital tools into their learning. But the nostalgia of touching books and dictionaries is still preserved. Some learners are the touchy-feely type. They prefer to feel the pages of dictionaries under their fingers. These are some of the things that electronic dictionaries cannot offer learners. Regarding this point, Laufer and Levitzky- Aviad (2006) express that print dictionaries have symbolic values and add that they are much healthier compared to electronic ones.

Setting out from the results of this study, it can be concluded that there are advantages and disadvantages in using print and online dictionaries. The common point highlighted by most researchers conducting studies on dictionaries is that teaching learners appropriate strategies to utilize dictionaries and training them is important (Carduner, 2003; Chan, 2011; Chon, 2008). Some previous studies have revealed that learners are not much educated in dictionary use (Chan, 2011; Nesi \& Meare, 1994) which results in the misuse of dictionaries as fundamental language materials. Therefore, a basic pedagogical implication to suggest, in the light of the results of this study and previous research, is that it is essential to raise learners' awareness of dictionary not as a source to provide word meanings but as a source to enrich their language knowledge and skills. Learners need to know that they can obtain much information through dictionaries and it is crucial to develop detailed searching skills (Carduner, 2003). Besides, foreign language teachers may not allocate much time for teaching how to use dictionaries effectively since they generally focus on improving the four skills of learners. However, if they include dictionary training in their language education, they may see the positive contribution of proper dictionary use to the progress of 
their students. And, this training can also be helpful for learners to develop learner autonomy which can aid them to direct their future learning experiences as they are equipped with the strategies to evaluate and control the learning process.

As this study was based only on qualitative data, future studies can investigate the issue with experimental designs or conduct surveys in order to find further evidence for a comparison of print and online dictionaries on quantitative basis. In order to strengthen the arguments, mixed studies involving participants from different contexts can be conducted. Besides, this study was conducted with third graders. In order to reach more comprehensive views, participants studying at different grades can be included in future research.

\section{Conclusions}

This study was conducted in order to gather the opinions of EFL learners as regards print vs. online dictionaries. For this purpose, classroom observations of the students taking Turkish-English Translation course and semi-structured interviews with a group of participants were conducted. The results revealed that although most of the participants used online dictionaries in practice as they offer speed access in short time, they also appreciated the advantages of print dictionaries mainly because they are more informative compared to online ones. Another point of appreciation of print dictionaries was the serendipity the participants could experience through their search. They could learn new words or remember the old ones which is generally not possible in online formats picturing only the searched item. The pedagogical suggestion that can be implied based on the results is that training learners in how to use dictionaries is essential in equipping them with appropriate strategies to benefit from dictionaries as fundamental self-learning materials.

\section{Notes}

Note 1. An initial version of this paper was presented at the $2^{\text {nd }}$ International Symposium on Language Education and Teaching in Rome, Italy on 20-23 April, 2017.

\section{REFERENCES}

[1] Bishop, G. (2000). Developing learner strategies in the use of dictionaries as a productive language learning tool. The Language Learning Journal, 22(1), 58-62. DOI: $10.1080 / 09571730085200261$.

[2] Bower, J \& McMillan, B. (2007). Learner's use and views of portable electronic dictionaries. In K. Bradford-Watts (ed.), JALT 2006 Conference Proceedings. Tokyo: JALT,
697-708.

[3] Carduner, J. (2003) Productive dictionary skills training: What do language learners find useful? The Language Learning Journal, 28:1, 70-76, DOI:10.1080/09571730385200231

[4] Chan, A. (2005). Tactics employed and problems encountered by university English majors in Hong Kong in using a dictionary. Applied Language Learning, 15(1), 1-28.

[5] Chan, A. (2011). Bilingualised or monolingual dictionaries? Preferences and practices of advanced ESL learners in Hong Kong. Language, Culture and Curriculum, 24(1), 1-21. DOI: 10.1080/07908318.2010.510196.

[6] Chen, Y. (2010). Dictionary use and EFL learning: A contrastive study of pocket electronic dictionaries and paper dictionaries. International Journal of Lexicography, 23(3), 275-306.

[7] Chen, Y. (2011). Dictionary use and vocabulary learning in the context of reading. International Journal of Lexicography 25(2), 216-247.

[8] Chon, Y. (2008). The electronic dictionary for writing: a solution or a problem. International Journal of Lexicography, 22(1), 23-54. DOI: 10.1093/ij1/ecn034.

[9] Deng, L. (2006). Survey of the use of paper dictionaries and electronic dictionaries among college students. Lexicographical Studies, 1, 172-181.

[10] Dziemianko, A. (2010). Paper or electronic? The role of dictionary form in language reception, production and the retention of meaning and collocations. International Journal of Lexicography 23(3), 257-273.

[11] Dziemianko, A. (2011). Does dictionary form really matter? In Akasu, K. and U. Satoru (eds), ASIALEX 2011 proceedings lexicography: Theoretical and Practical Perspectives. Kyoto: Asian Association for Lexicography, 92-101.

[12] Dziemianko, A. (2012). Why one and two do not make three: Dictionary form revisited. Lexikos 22, 195-216.

[13] Folse, K. S. (2004). Myths about teaching and learning second language vocabulary: What recent research says. TESL Reporter, 37(2), 1-13.

[14] Gromann, D. \& Schnitzer, J. (2015). Where do business students turn for help? An empirical study on dictionary use in foreign-language learning. International Journal of Lexicography, 29(1), 55-99. DOI: 10.1093/ij1/ecv027.

[15] Hayati, A.M., \& Fattahzadeh, A. (2006). The effect of monolingual and bilingual dictionaries on vocabulary recall and retention of EFL learners. The Reading Matrix: An International Online Journal, 6(2), 125-134.

[16] Hyun Ma, J. \& Cheon, H. (2016). An experimental study of dictionary use on vocabulary learning and reading comprehension in different task conditions. Int $J$ Lexicography. doi: 10.1093/ij1/ecw037

[17] Laufer, B. (2000). Electronic dictionaries and incidental vocabulary acquisition: Does technology make a difference? In U. Heid (ed.), Proceedings of EURALEX 2000. Stuttgart: IMS, Universita“" t Stuttgart, 849-854. 
[18] Laufer, B., \& Hill, M. (2000). What lexical information do L2 learners select in a CALL dictionary and how does it affect word retention? Language Learning and Technology, $3(2), 58-76$.

[19] Laufer, B. \& Levitzky-Aviad, T. (2006). Examining the effectiveness of bilingual dictionary plus'- a dictionary for production in a foreign language. International Journal of Lexicography, 19(2), 135-155. doi:10.1093/ij1/eck006

[20] Lew, R. \& Doroszewka, J. (2009). Electronic dictionary entries with animated pictures: Lookup preferences and word retention. Int J Lexicography, 22(3), 239-257. DOI: https://doi.org/10.1093/ij1/ecp022

[21] Kobayashi, C. (2006). The use of pocket electronic dictionaries as compared with printed dictionaries by Japanese learners of English. PhD Thesis, The Ohio State University.

[22] Koga, Y. (1995). The effectiveness of using an electronic dictionary in second language reading. Bulletin of the Liberal Arts of Hiroshima University, 44, 239-244.

[23] Koyama, T. \& Takeuchi, O. (2003). "Printed dictionaries vs. electronic dictionaries: A pilot study on how Japanese EFL learners differ in using dictionaries. Language Education and Technology, 40, 61-79.

[24] Koyama, T. \& Takeuchi, O. (2004). Comparing electronic and printed dictionaries: How the difference affected EFL learning. JACET Bulletin, 38, 33-46.

[25] Koyama, T. \& Takeuchi, O. (2007). Does look-up frequency help reading comprehension of EFL learners? Two empirical studies of electronic dictionaries. CALICO Journal, 25 (1), 110-125.

[26] Nesi, H. (1999). A user's guide to electronic dictionaries for language learners. International Journal of Lexicography, 12(1), 55-66.

[27] Nesi, H., \& Meara, P. (1994). Patterns of misinterpretation in the productive use of EFL dictionary definitions. System, 22(1), 1-15.

[28] Ranalli, J. (2013). Online strategy instruction for integrating dictionary skills and language awareness. Language Learning \& Technology, 17(2), 75-99.

[29] Yang, B \& Zhao, J. (2007). A contrastive study of paper dictionaries and palmtop dictionaries in collocation. Hope Monthly, 2, 21-22. 